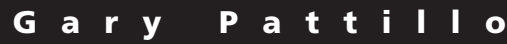
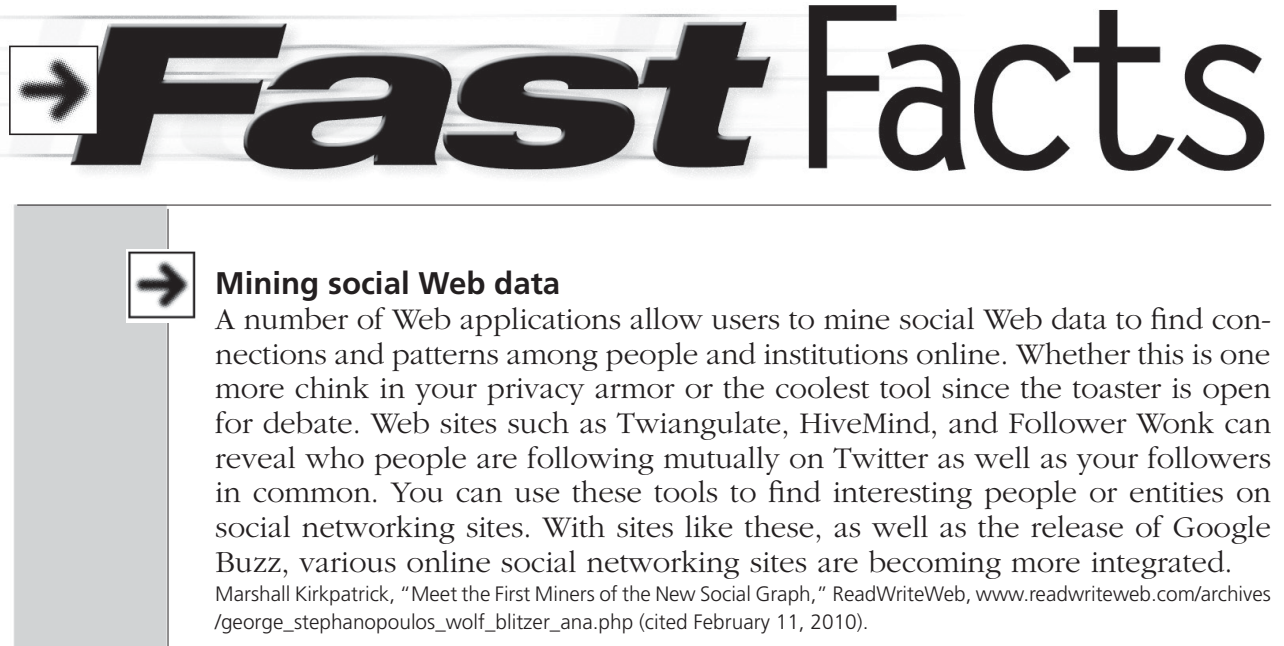

/george_stephanopoulos_wolf_blitzer_ana.php (cited February 11, 2010).

\section{Search trends}

What do Twitter, Michael Jackson, Facebook, and Hulu have in common? They are among the most rapidly rising search terms on Google during the past 12 months. Google Zeitgeist and its related tools, such as Insights For Search, enable users to examine the billions of queries that people around the world have typed into the Google search engine. Search limiters include region, date, category, metro region, and search terms.

Marissa Mayer, "Zeitgeist 2009: The Collective Consciousness," Google, Inc. googleblog.blogspot.com/2009/12/zeitgeist2009-collective-consciousness.html (cited January 8, 2010).

\section{Real-time search}

In a recent article, Phil Bradley discusses the concept of real-time search and highlights some of the functionality that users can expect to find with these online tools. "Real-time search" includes the ability to find something on the Web that was made available in the last few seconds or hours. Twitter's search function is the most well-known, but aggregate search engines, such as Collecta, index content from several sources simultaneously (Flickr, Twitpic, Twitter, Youtube, etc.). Another-CrowdEye-provides access to popular searches and the current top 20 Web sites.

Phil Bradley, "Search Engines: Real-time Search," Ariadne, issue 61, October 2009 (cited December 18, 2009). Available at www.ariadne.ac.uk/issue61/search-engines/.

\section{Climate.gov}

A new Web site will serve as a single point of entry for National Oceanic and Atmospheric Administration climate information, data, products, and services. This climate portal will provide information about the impacts of climate on many areas, such as agriculture, energy, transportation, economics, and research. Climate.gov features a Global Climate Dashboard providing interactive data visualization for measurements, such as temperature, sea level, carbon dioxide, and Arctic sea ice. The site contains links to a wealth of data and educational resources.

"Commerce Secretary Gary Locke and NOAA Administrator Jane Lubchenco Unveil Landmark Climate.Gov Porta to Climate Information," NOAA-National Oceanic and Atmospheric Administration, www.noaanews.noaa.gov /stories2010/20100208_climategov.html (cited February 9, 2010).

Gary Pattillo is reference librarian at the University of North Carolina-Chapel Hill, e-mail: pattillo@email. unc.edu 